MATEC Web of Conferences 37, 01004 (2015)

DOI: $10.1051 /$ matecconf $/ 20153701004$

(C) Owned by the authors, published by EDP Sciences, 2015

\title{
RESEARCH OF RELIABLE POWER SUPPLY SCHEMES FOR OOO GAZPROM PRODUCTION YAMBURG GAS FIELD
}

\author{
Alisher Askarov ${ }^{1}$, Mikhail Kondrashov ${ }^{1}$, Nina Kosmynina ${ }^{1, a}$ \\ ${ }^{1}$ National Research Tomsk Polytechnic University, 634050, Tomsk, Russia
}

\begin{abstract}
In article the analysis of substation electric part for the enterprises an oil and gas complex power supply is carried out: structure and switchgear schemes, uninterrupted reserve sources structure. Recommendations for power supply reliability are made.
\end{abstract}

\section{Introduction}

The uninterrupted power supply is important part of enterprises optimum operating conditions. According to "Rules of the electrical equipment operation " (REEO) for each category of electroreceivers power supply reliability requirements are defined, some objects have to be provided with own additional uninterrupted sources of reserve power supply [1]. Within given articles ways of ensuring power supply one of Gazprom objects are considered.

The "Gazprom production Yamburg" is founded in 1984 in the Yamburg settlement. The gas field $1 \mathrm{~V}(\mathrm{GP}-1 \mathrm{~V})$ is a part of the Valanginian deposit gas fields of the Yamburg oil-gas condensate field

According to requirements STO Gazprom 2-6.2-149-2007 "Categorization of electroreceivers of Gazprom industrial facilities" [2] GP-1V main technological loadings belong to the first category of power supply reliability. Thus from structure electroreceivers of the first category at this enterprise the special group is allocated: automated control system for technological process, instrumentations and automatic equipment.

Electroreceivers of the first category have to be provided with the electric power from two independent mutually reserving power supplies, and for electroreceivers of the first category special group additional food from the third the independent mutually reserving power supply for the higher power supply reliability [1].

\section{Experimental setup and study technique}

The block diagram of GP - 1B gas field power supply is shown in Fig. 1. The main and reserve GP$1 \mathrm{~V}$ power supply is carried out from two power supply independent sources on VL-110 kV airpower lines from Yamburg substation and Yamburg gas-turbine power plant (see Fig. 1).

On GP-1V substation two TDTN transformers - 25000/110, lowering voltage of $110 \mathrm{kV}$ to $35 \mathrm{kV}$ and $6 \mathrm{kV}$ are installed. The choice of each transformers power is made taking into account an

a Corresponding author: kosm_nm@tpu.ru

This is an Open Access article distributed under the terms of the Creative Commons Attribution License 4.0, which permits unrestricted use, distribution, and reproduction in any medium, provided the original work is properly cited. Article available at $n$ ttp://www.matec-conterences.org or $n$ ttp://dx.dol.org/10.1051/mateccont $/ 20153 / 01004$ 
emergency overload that allows to provide power supply of consumers at a shutdown from work of one of transformers.

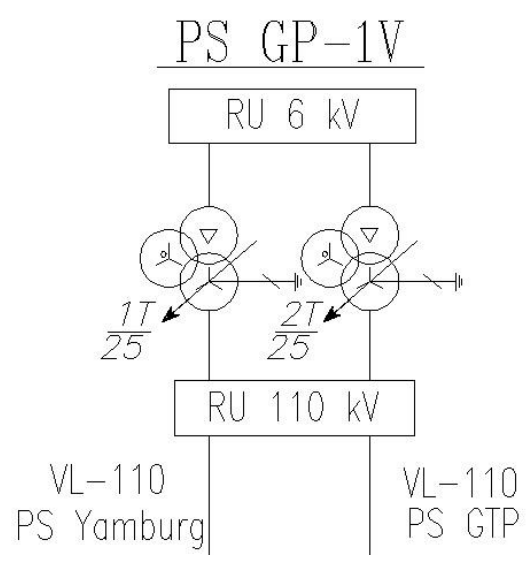

Figure 1. Block diagram of gas field power supply

The $110 \mathrm{kV}$ switchgear is executed according to the scheme of the bridge with switches in lines chains and a repair connection from lines. This scheme has 3 cells on 4 attachment; the minimum alienated areas; low cost of RU is noted. The analysis of normal and emergency operation of RU showed that the scheme has serious defect: at failure of the switch in the bridge there is a repayment of all RU; failure of the power transformer will bring to loss of power transit. In this regard transition to the scheme of a quadrangle is offered.

The scheme has 4 cells on 4 attachment - increase in switches number in comparison with the bridge scheme. Insignificant increase in cost indexes (the cost of one $110 \mathrm{kV}$ switch) is compensated simplification of service conditions, relay protection and automatic of electric equipment of RU due to the lack of a repair connection. It should be noted one more important advantage of the offered scheme: failure of one switch leads to shutdown no more than one line and one transformer whereas in case of the bridge there is a repayment of all RU.

The switchgear of $6 \mathrm{kV}$ is executed by complete (CRU) or the metal-clad switchgear for the international practice [3]. CRU is the standard decision for schemes of this voltage. The CRU are convenient in installation and operation: compactness allows to lower costs of construction installation works; the arrangement of elements allows to serve most conveniently CRU. It should be noted high safety due to localization of accident within one compartment of CRU that ensures safety of the personnel and safety of the expensive equipment; the system of mechanical and electromagnetic blocking prevents possibility of wrong actions personnel.

The Russia industry made a large number of CRU, electric equipments differing in structure. On substation CRU with vacuum VKE-10 switches are installated. The vacuum switch arch dies away in the rarefied space. Electric durability of vacuum is extremely high and is very quickly restored after electric breakdown. Switches have high reliability and the reduced costs of service, simplicity of a design. Nevertheless the high cost of the device and possibility of an overvoltage in a network at its certain states is noted.

It is offered to carry out modernization of CRU by replacement of vacuum switches by the SF6 gas switches. Advantages of SF6 gas switches: the small weight and overall dimensions of designs in combination with silent operation of the drive; optimum process of arc extinction in the closed gas volume without access to the atmosphere; harmlessness for the person, the environmentally clearly, inert gas environment of the gas switch; the increased switching ability; high reliability; fire safety of the equipment. The SF6 gas switches in total with complete distributive devices are widely used in practice of the international power community [5]. The next ways of modernization are offered. The first - replacement of the used CRU on other types CRU with SF6 gas switches, for example, K-61M, 
K-XXVI, K-XXVII or CRU of SVEL Group - the leading Russian producer of the electrotechnical equipment [6]. The second - replacement only the elements roll out established in CRU on the module with the SF6 gas switch.

The $6 \mathrm{kV}$ switchgear is executed according to the scheme one switchable busbar, that is the standard practice for RU of this voltage [5]. Advantages of this scheme: simplicity, profitability, localization of power failure within one section. However the scheme has a number of defects. For example, damage of the section switch leads to shutdown of all RU. Therefore it is recommended to work at the -off - line section switch. More serious defects of the scheme: repair of one section, leads to the power outage of all section consumers. For an exception of it in the scheme power supply reservation for separate consumers is put: obvious (power supply from several cells) or implicit reservation (redistribution of loading in normal and emergency operation). All these measures are provided on this RU therefore transition to more difficult scheme is inexpedient.

The offered improvements of substation electric part corresponds to the international experience in this direction [4].

On GP-1V substation reserve sources are installed. The mobile automated gas-turbine power plants of PAES-2500 are connected to the 1st and 2nd tires sections of CRU-6 kV (see Fig. 2, a). Power of PAES is sufficient for power supply of all consumers in case of a total disappearance of external power supply. At a choice of reserve sources the total power of probable consumers of energy, and also development of producers was considered [6].

The power plant consists of a gas turbogenerator, the switchgear CRU-6, the control panel and the service equipment. Everything is mounted in the special semi-trailer van. The drive of the synchronous SGS-14-100-6U2 generator is the gas-turbine aviation turbo-propeller AI-20 engine. The engine is connected to the generator by the elastic coupling. Management and control of engine, the generator and CRU operation is carried out from the control panel.

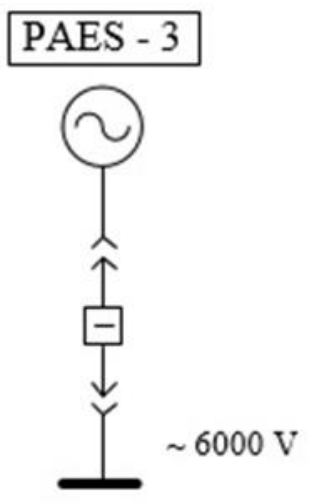

a)

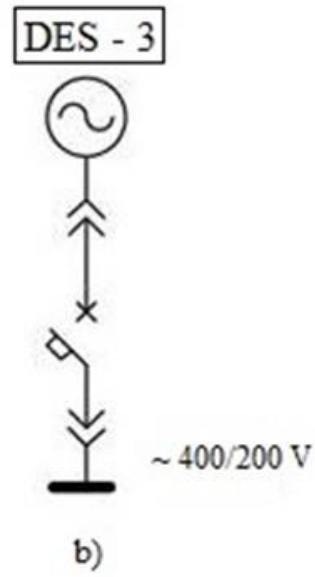

Figure 2. Schemes of reserve and emergency power supplies connection: a) mobile automated power plant; b) diesel power plant

For automatic control of PAES-2500 the EG-2500 system is used. The EG-2500 is developed on the basis of microprocessor local information managing directors of systems that provides high extent of management automation and control is used. This system possesses high resistance to external influences.

In addition as emergency electric supplies two diesel power plants (DES) of "BES-630" and DKS "Star 630-HK01" are installed. The choice DES as emergency power supplies was based on a variety of reasons [5]:

1. The basis of DES is made by the diesel engine having a number of advantages in comparison with other types of internal combustion engines: the smaller cost and fuel consumption, bigger motor potential, high reliability, less strict requirements to quality of fuel, rather high fire safety; 
2. The gas field itself makes necessary fuel for DES that solves one of the main components of expenses in prime cost of the electric power developed by diesel power plants - costs of expensive fuel;

3. Rather high DES efficiency (to 0.35-0.4), speed of start-up (unit ten of seconds) and high maneuverability at accident emergence.

DES - 1 is intended for power supply of auxiliary buildings and constructions, DES - $2-$ for power supply of methanol regeneration department and DES - 3 - for power supply of the production and power block; the scheme of connection of DES is given in fig. 2. Diesel power plants allow to carry out power supply of GP-1V consumers during emergency and sudden disappearance of the main food. In addition, DES "Star 630-HK01" is started together with PAES. The entrance of PAES to a nominal operating mode requires about 5-10 minutes, thus gas-distributing units shouldn't stop, differently it can lead to explosions and catastrophic consequences. The DES No. 1, 2 and 3 power are calculated on for deduction of the main units and installations in rather steady modes provide power supply till that time until all PAES enter a nominal operating mode.

\section{Experimental results}

In article the substation scheme intended for power supply of the oil - gaz complex enterprises are analyzed: structure, external power supply, $110 \mathrm{kV}$ and $6 \mathrm{kV}$ switchgear schemes, and also additional sources of reserve power supply.

\section{Conclusion}

The scheme analysis of substation power supply showed the following.

The main and reserve power supply of GP-1V is carried out from two independent sources of power supply on VL-110 kV air-power lines.

On substation two power transformers are established that allows at a conclusion from work of one of them to provide consumers power supply.

The RU $110 \mathrm{kV}$ electric connections scheme is the bridge with switches in lines chains and a repair connection from lines. The scheme won't be able to provide reliable receiving the electric power from an external network of $110 \mathrm{kV}$ at a combination of the adverse modes, therefore it is offered to pass to schemes of a quadrangle.

Power supply of gas field consumers is carried out from CRU $6 \mathrm{kV}$. The $6 \mathrm{kV}$ switchgear is executed according to the scheme one switchable busbar. This scheme with use of the complete equipment (CRU) meets the requirements of reliability. The CRU switching devices is vacuum switches, during which work perhaps of overstrain emergence at certain network states. Therefore it is offered to carry out modernization of CRU electric equipment by replacement vacuum switch on the gas-insulated.

On PS are established mobile automated gas-turbine (PAES) and diesel power plants (DES), allowing to ensure consumers autonomous functioning at total absence of external power supply.

The considered power supply scheme meets the requirements of continuous power supply of the electroreceivers first category and first category special group. The offered technical actions will allow to provide reliability of power supply in a bigger measure.

\section{References}

1. Rules of the electrical equipment operation (Moscow: Knorus, 2014)

2. STO Gazprom 2-6.2-149-2007. Categorization of electroreceivers of Gazprom industrial facilities. $-17 \mathrm{p}$

3. C37.20.2-2015 Standard for Metal-Clad Switchgear (IEEE, 2015)

4. Technical brochure 532 WG B3.23. Electra, 267, 41 (2013) 
Smart Grids 2015

5. P.Glaubitz, P.Rudenko, W.Shen D.Li. International Conference on High Voltage Engineering \& Application, 1 (1), 509 (2012)

6. The energy saving equipment and technologies for energy production, transfers and distributions (Moscow: Information electro, 2001) 